\title{
O desmantelamento do direito \\ à educação no pós golpe
}

\section{The dismantling of the right to}

education in the post-coup

\section{El desmantelamiento del derecho}

a la educación en el post golpe

\author{
JOÃO PAULO DE SOUZA DA SILVA* \\ Universidade Federal do Paraná, Curitiba- PR, Brasil. \\ DANIELLE SCHEFFELMEIER MEI ${ }^{* *}$ \\ Universidade Federal do Paraná, Curitiba- PR, Brasil.
}

\begin{abstract}
RESUMO: O objetivo deste artigo é discorrer sobre o desmantelamento de direitos que está diretamente ligado ao golpe de 2016. Fazendo um recorte temporal de 2013 a 2017, este trabalho visa relacionar as políticas de austeridade com a redução de investimentos na educação, com as mudanças na legislação de maneira muito acelerada e sem debate público coerente e consciente. $\mathrm{O}$ artigo toma como ponto de partida as marchas de 2013, quando uma camada da população que historicamente não ocupava as ruas por reivindicações entra em cena, fazendo movimentações amorfas e sem objetivos comuns.

Palavras-chaves: Reformas educacionais. Congelamento de investimentos. Golpe de 2016.
\end{abstract}

\begin{abstract}
The objective of this article is to discuss the dismantling of rights directly related to the coup of 2016. Making a time frame from 2013 to 2017, this work aims to relate the austerity policies with the reduction of investments in education, with the very quick changes in
\end{abstract}

\footnotetext{
* Mestre e Doutor em Educação pela Universidade Federal do Paraná. Professor da Faculdade São Braz (Curitiba), nos cursos de licenciatura em Pedagogia e bacharelado em Teologia. Professor da rede pública municipal de ensino de Curitiba. E-mail: <jpaulodesouza@hotmail.com>.

* Mestra em Comunicação e mestranda em Educação pela Universidade Federal do Paraná. É graduada em Jornalismo. E-mail:<dani_mei@hotmail.com>.
} 
legislation without coherent and conscious public debate. The article takes the marches of 2013 as starting point, when a specific part of the population that historically did not occupy the streets for demands, enters the scene, doing amorphous movements with no common objectives.

Keywords: Educational reforms. Investment freezing. Coup of 2016.

RESUMEN: El objetivo de este artículo es discurrir sobre el desmantelamiento de derechos que está directamente ligado al golpe de 2016. En un recorte temporal de 2013 a 2017, este trabajo busca relacionar las políticas de austeridad con la reducción de inversiones en la educación, con los cambios en la legislación de manera muy acelerada y sin debate público coherente y consciente. El artículo toma como punto de partida las marchas de 2013, cuando una capa de la población que históricamente no ocupaba las calles por reivindicaciones entra en escena, haciendo movimientos amorfos y sin objetivos comunes.

Palabras clave: Reformas educacionales. Congelación de inversiones. Golpe de 2016.

\section{Introdução}

E ste trabalho objetiva traçar um panorama dos ataques estabelecidos em face da educação pública e dos educadores, a partir do ano de 2016, quando a presidenta Dilma Rousseff foi afastada de seu mandato, após golpe parlamentar. Compreende-se que as diversas agressões contra os direitos historicamente e socialmente construídos ao longo de décadas pelas gerações passadas não se configuram em mera coincidência, ao contrário, se caracterizam como estratégia de manutenção de poder, por parte dos que se estabeleceram por meio do Golpe de Estado. Para tanto, o artigo faz um recorte temporal desde as chamadas "marchas de 2013" até o final de 2017, ano em que foram aprovadas diversas medidas que comprometem o futuro da educação brasileira, além do corte nos investimentos sociais.

O fim da destinação dos recursos do pré-sal para educação, o congelamento dos investimentos sociais por 20 anos, a implementação da Base Nacional Curricular Comum (BNCC), o projeto "Escola Sem Partido", a reforma do ensino médio são apenas diferentes frentes de desconstrução do ideal de uma escola pública, laica, gratuita e de qualidade, no horizonte da educação brasileira, pelo menos desde a publicação do Manifesto dos Pioneiros da Educação Nova, no ano de 1932. 


\section{$\mathrm{O}$ "gigante" acordou}

Em 6 de junho de 2013, um grupo se reuniu na Avenida Paulista, em São Paulo, para protestar contra o aumento de 20 centavos no preço das passagens de ônibus, segundo informações do jornal Folha de São Paulo ${ }^{1}$. O Movimento Passe Livre (MPL) não tinha noção, naquele momento, do que se tornaria essa manifestação, considerada então o marco zero das chamadas "Marchas de 2013". As marchas aconteceram em diversas cidades do Brasil e iniciaram com o lema "Não era pelos 20 centavos", porém, as bandeiras não pararam aí:

Junho de 2013 também carrega uma multidão de reivindicações, frustrações e aspirações. Não foi por acaso que o aumento das tarifas e a realização de grandes eventos esportivos no país catalisaram insatisfações de ordens tão diferentes. O transporte público é exemplar de ineficiência, má qualidade e preço exorbitante. Pelo menos desde 2003, vinha se organizando um movimento nacional (o Movimento Passe Livre, MPL), com manifestações importantes contra todos os episódios de aumentos de tarifa. Comitês Populares da Copa se formaram nas cidades-sede do campeonato mundial de futebol para denunciar violações de direitos e para questionar os supostos benefícios que viriam com os gastos públicos com a organização. São movimentos que se formaram e que funcionam de maneira apartidária, mantendo autonomia e independência em relação a governos. São movimentos horizontais, que recusam a ideia da concentração da representação em uma liderança individual. A violenta repressão policial aos protestos que iniciaram pelo país desencadeou uma onda ainda maior de mobilização, tanto em defesa do direito constitucional de manifestação como contra a atuação da polícia em geral. E uma série de reivindicações veio se juntar às iniciais (NOBRE, 2013, pg. 4).

Com ações coletivas desencadeadas a partir desse evento, as diversas manifestações movimentaram as ruas do País, demonstrando a insatisfação da população em relação a temas diversos. Tendo em vista que o movimento não tinha um objetivo comum, o que se percebeu foi um "gigante amorfo", com diversas vozes e que não tinha características clássicas dos movimentos sociais, já organizados em torno de causas e que, tradicionalmente, promovem ações e protestos.

Nesse momento, estavam na rua, pela primeira vez, sujeitos advindos de classes sociais que, historicamente, não costumavam ocupar as ruas, dividindo o espaço com os movimentos sociais organizados, estabelecendo uma ambiguidade que

Também resulta em mais de uma forma de identificação na política dos sujeitos-atores que compareceram às ruas em 2013: por um lado, os identificados com movimentos sociais e (ou) partidos políticos; por outro, os participantes individuais, convocados, sobretudo, pelas mídias digitais. Essas duas formas de ser sujeito político geraram as contradições e os conflitos políticos presentes no processo mobilizatório, o que levou os vários analistas das manifestações às incertezas sobre as possibilidades ou não de novas manifestaç̃es em 2014 e (ou) sobre o futuro político dos processos mobilizatórios nas ruas (Scherer-Warren, 2014). 
Como resultado imediato, o Brasil assistiu a uma quantidade imensa de pessoas na rua reivindicando assuntos diversos, o que torna essas marchas um indício de insatisfação, mas sem organização e planejamento. O gigante acordou, foi para a rua e depois voltou para casa e a ordem naturalizada cotidiana foi retomada. No entanto, a popularidade da presidenta Dilma Rousseff caiu oito pontos naquele momento, a maior queda desde que ela assumiu o mandato, em 2010. E a descrença dos brasileiros nos serviços públicos, na ordem política e no futuro do País cresceu a olhos vistos.

\section{4: A Lava Jato e as eleições}

O ano de 2014 foi marcado por dois momentos importantes no contexto político nacional: a eleição presidencial e o início da Operação Lava Jato² em 17 de março de 2014, antes do anúncio oficial das candidaturas dos presidenciáveis. Caracteriza-se como a maior operação ${ }^{3}$ sobre corrupção no Brasil, envolvendo doleiros, políticos, empreiteiras e os desvios de verbas em empresas públicas, como a Petrobras. Resultou em seis sentenças, 37 condenações, mais de 452 milhões de reais ressarcidos em acordos de colaboração.

A Lava Jato tem um princípio de ação louvável, com a perspectiva de condenação de um grupo de pessoas que, historicamente, estava acima da lei, o que só foi possível em um governo com inspirações mais voltadas ao interesse geral da população. Mas, ao que parece, as ações da Lava Jato se mostraram parciais ${ }^{4}$ ao longo do tempo, tendo em vista que os políticos ligados a determinados grupos não são investigados. Contudo, após quatro anos de existência, a operação é problematizada por parte significativa da população e da intelectualidade como mecanismo de perseguição política a determinados líderes partidários.

Outro ponto alto do ano de 2014 foi a eleição presidencial ${ }^{5}$, muito acirrada, tendo no final do pleito os candidatos Dilma Rousseff (PT) e o vice Michel Temer; concorrendo com Aécio Neves (PSDB) e o vice Aloysio Nunes Ferreira. O resultado foi bem apertado e a chapa Dilma-Temer foi eleita com 51,65\% dos votos válidos (54.483.045 Votos). Aécio-Ferreira ficou com 48,35\% dos votos (50.993.533). Os votos brancos e nulos somaram cerca de seis milhões, ou 6,34\%.

É interessante destacar que a campanha foi marcada por diversas pesquisas de opinião confusas ao longo do período, além de uma expectativa do empresariado e elites que a chapa de Aécio venceria na ocasião, o que não aconteceu. Apesar de todas as denúncias e as marchas de 2013, que ainda estavam recentes na memória das pessoas, o governo de situação foi reeleito. 


\section{5: Crise do governo Dilma}

O ano de 2015 foi marcado por crises no governo Dilma, além de uma divisão teoricamente ideológica da população que acarreta o afastamento da presidenta no ano seguinte. A Carta Maior ${ }^{6}$ elenca as crises da aliança de classes, a crise econômica e a política.

A primeira diz respeito ao esgotamento do "modelo de pactuação da renda com a ampliação econômica do mercado interno", mas a configuração política não estava alinhada. A crise de alianças foi percebida em relação às classes médias, que não tinham seus interesses representados neste momento; à classe produtiva, que viu seus rendimentos caindo; à mídia, que diariamente publicava notícias negativas em relação à economia e à situação política, causando uma sensação de desconfiança por parte da população. A aliança de classes mostra um enfraquecimento, demonstrando ainda mais a ruptura e a divisão de opiniões e interesses.

A segunda crise destacada na reportagem de Francisco Fonseca é a institucional, do estado de direito, e a mobilização das elites. As investigações das operações policiais da época demonstravam a parcialidade das prisões, e a mídia seguiu seu espetáculo: quase não se vê a conversa pública, já que a mídia tomou esse espaço, substituindo-o pelos espetáculos da televisão (manipulados), no exemplo das eleições políticas e, agora, ao publicar grande quantidade de notícias e conteúdos relacionados à crise.

Mas a contraparte da crise do Estado de Direito Democrático é a mobilização das classes médias e segmentos das elites econômica, política e intelectual em prol do impeachment da presidente Dilma e do extermínio do PT e das pautas progressistas. Tais elites, que se beneficiaram fortemente da ampliação do mercado interno (crédito e consumo), da política exterior diversificada e do desenvolvimento econômico e social como um todo, o que inclui a superação do crash de 2008, voltam-se fervorosamente contra a presidente, seu partido e sua principal liderança em razão do ódio de classes, ancorado no imemorial privilégio de classes havido no Brasil, e sequer superado, apenas amenizado (FONSECA, 2015).

Para completar o cenário que precede o golpe de 2016, a crise econômica internacional tem reflexos na economia brasileira. No entanto, essa crise pareceu efetivamente mais política, pois demonstrava com clareza que as classes dominantes não apoiariam mais as medidas sociais adotadas pelos governos Lula e Dilma. Além disso, a divisão de renda não seria cogitada por grandes empresários nacionais que viam seus lucros reduzidos.

\section{6: o ano que não terminou}

Com o afastamento da presidenta eleita Dilma Rousseff, Michel Temer assume interinamente o cargo de presidente em maio de 2016. Uma das suas primeiras ações foi nomear apenas ministros homens, o que não representa a maioria da população brasileira, 
composta por mulheres e negros, o que cria, obviamente, um desconforto: os homens que decidiriam boa parte dos destinos do Brasil não tinham a cara da população brasileira.

Dilma Rousseff foi afastada em definitivo do cargo em 31 de agosto de 2016. Após esse fato, uma série de medidas impopulares começa a ser lançada pelo Governo federal e que ferem diretamente a educação. A constar: a Proposta de Emenda Constitucional nํㅡㄴ 241 (depois PEC 55), que congela os gastos públicos por 20 anos; a reforma do ensino médio, via Medida Provisória (MP), e o projeto de lei batizado de "Escola sem Partido" ou "Lei da Mordaça", com impacto direto na atuação docente.

Em outubro de 2016, escolas e universidades de 20 estados e do Distrito Federal passaram por um movimento de ocupação contra a reforma do ensino médio, prevista na Medida Provisória (MP) 746, e contra a Proposta de Emenda à Constituição (PEC) 55, que restringe os investimentos sociais do Governo federal, inclusive em educação, ambas propostas do Governo Temer.

Além disso, a extinção do Ministério da Cultura causou manifestações dos artistas e profissionais da área. A interpretação que se faz a respeito deste episódio é que, com a unificação das pastas de Educação e Cultura, a segunda acaba por receber menos investimentos, em um governo marcado por políticas de austeridade.

O número de escolas ocupadas no Paraná contra a reforma do ensino médio, proposta por Michel Temer, chegou a cerca de 900. O movimento, que teve início em São José dos Pinhais, no dia 3 de outubro, se espalhou para todos os cantos do estado. A insatisfação com o atual modelo de governo se acentua no Paraná devido ao 29 de abril de 2015, quando o governador paranaense Beto Richa autorizou uma ação da polícia militar para reprimir uma manifestação de professores e professoras. Eles decidiram pela paralisação devido a votação que autorizava o Governo estadual a mexer na Previdência para cobrir outros gastos. Como resultados, 200 pessoas ficaram feridas e a medida foi aprovada. Como forma de protesto e para relembrar a data, não há aulas nas escolas estaduais do Paraná nesta data (MEI, SILVA, 2017).

\section{Entre o teto e o assoalho do Estado: a EC 95}

A emenda constitucional no 957, de 15 de dezembro de 2016 “altera o Ato das Disposições Constitucionais Transitórias, para instituir o Novo Regime Fiscal, e dá outras providências". A alteração, resultado dos projetos de Emenda Constitucional 241 e 55, estipula um limite de investimentos públicos nos próximos 20 anos, e ficará vigente até 2036. A votação foi precedida de muitos protestos por parte da sociedade civil organizada, em especial estudantes de universidades públicas, que classificaram o projeto como prejudicial para o desenvolvimento da educação a longo prazo. 
Outra questão que surge ao longo do processo de tramitação desta legislação é que houve, por parte do Governo federal e da mídia, a utilização de um discurso que classificava a PEC como necessária para estabilizar os gastos. Cynara Monteiro Mariano (2017) analisa as consequências a longo prazo:

As regras do novo regime não permitem, assim, o crescimento das despesas totais e reais do governo acima da inflação, nem mesmo se a economia estiver bem, o que diferencia o caso brasileiro de outras experiências estrangeiras que adotaram o teto de gastos públicos. Somente será possível aumentar os investimentos em uma área desde que sejam feitos cortes em outras. As novas regras desconsideram, portanto, as taxas de crescimento econômico, como também as demográficas pelos próximos 20 (vinte anos), o que (e aqui já antecipando a nossa crítica a respeito), poderá levar ao sucateamento das políticas sociais, especialmente nas áreas da saúde e educação, pondo em risco por completo a qualidade de vida da população brasileira (MARIANO, 2017, p. 261).

Segundo a autora, essa medida terá consequências, ainda, no investimento em novas tecnologias, contratação de pessoal, reajuste salarial, entre outros. Além disso, impedirá a ampliação do atendimento à população, sendo que os investimentos somente serão calculados pelo percentual da inflação. Em notícia publicada no jornal O Globo ${ }^{8}$ em 26 de junho de 2016, o então ministro da Fazenda, Henrique Meirelles sinalizava a desvinculação das despesas com saúde e educação como uma medida para solucionar o "engessamento do orçamento", além de ser a bandeira utilizada pelo governo, na conjuntura, para conter as despesas governamentais, o que não se aplica na prática.

Os tributos são as contribuições compulsórias pagas por todos os cidadãos ao efetuar compras ou pagar contas. Os tributos são classificados em impostos, taxas e contribuições de melhoria. Os impostos incluem, por exemplo, Imposto sobre Exportação, Imposto de Renda e Imposto sobre Produtos industrializados, e são os recursos destinados obrigatoriamente à educação. Atualmente, a União deve investir 18\% dos impostos na educação. Os estados e municípios devem destinar pelo menos $25 \%$ cada e esses recursos devem ser investidos na Manutenção e Desenvolvimento do Ensino (MDE).

O problema desse sistema é que a União arrecada mais e é a que menos investe efetivamente na educação básica. Além disso, a arrecadação dos estados e municípios é muito menor que a da União, gerando desigualdade no acesso à educação básica. Quando os municípios assumem a responsabilidade pela educação infantil e ensino fundamental, a União se isenta da responsabilidade constitucional de garantir acesso à educação básica.

Além disso, a educação infantil e ensino fundamental somam o maior número de matrículas, e recebem menos verbas, já que são mantidos por meio dos recursos dos estados e municípios. Com as desigualdades dos municípios do Brasil, muitos apresentam condições financeiras baixas para investir efetivamente em educação.

Ao defender que a redução de investimentos em áreas estratégicas seria a "salvação" para as contas do governo, não se considerou a taxação de grandes fortunas como 
solução para os problemas econômicos. Ao comparar os dados ${ }^{9}$ de salário e alíquotas de Imposto de Renda, é possível perceber que as pessoas que recebem os salários mais altos do Brasil são as que menos pagam impostos, ou seja, tem mais renda quem está fora da taxação. Uma pessoa que recebe aproximadamente dez salários mínimos paga a mesma porcentagem de impostos de alguém que recebe 70 salários. Isso indica que a porcentagem é a mesma, mas as diferenças de faixa salarial são grandes.

Com isso, as grandes fortunas continuam intactas, pois não são tributadas, o que gera ainda mais desigualdade. Por outro lado, em relação aos impostos pagos pela população em geral, o Brasil tem uma carga tributária de 33,7, abaixo dos 35, que é a média da Organização para a Cooperação e Desenvolvimento Econômico (OCDE). No entanto, cerca de 50\% dos impostos pagos no País são sobre bens e serviços, itens básicos para a manutenção das famílias, incluindo itens como mercado e combustível. Esses impostos são pagos igualmente por pessoas com rendas totalmente distintas, o que torna o cenário injusto para aqueles que recebem menos e têm de pagar os mesmos impostos do que as pessoas que recebem muito. Por outro lado, o imposto pago sobre os ganhos ou lucros soma apenas $6 \%$ dos $33 \%$ pagos, indicando que as pessoas com maior renda pagam menos impostos, ou pagam ainda muito pouco.

\section{A BNCC como controle/engessamento da educação}

As discussões sobre as bases nacionais comuns não são novas no Brasil. Na década de 1990, os Parâmetros Curriculares Nacionais já sinalizavam para um currículo comum orientado pelas reformas da educação no Governo Fernando Henrique Cardoso, com forte viés centralizador. Já nos anos 2000, há a definição das Diretrizes Curriculares Nacionais da Educação em todos os níveis, culminando, em 2010, na aprovação pelo Conselho Nacional de Educação das Diretrizes da Educação Básica. Esse documento legisla sobre os diferentes níveis e modalidades da educação infantil ao ensino médio.

Antes mesmo de se perguntarem se faz sentido uma base comum nacional ou um currículo mínimo nacional, educadores dos mais diferentes lugares, formações e campos de atuação estão se debruçando sobre as listagens de objetivos elaboradas por especialistas a pedido do MEC e que em muitos aspectos remetem à taxionomia de objetivos que marcaram a política curricular nacional em tempos de ditadura civil-militar.

Contudo, no que se refere à formulação de uma base nacional comum, reforçamos a preocupação de que tal base venha a se tornar um currículo único e mínimo, desprezando a diversidade, a autonomia escolar e a criação docente. O currículo mínimo, a pretexto de servir de mecanismo para se atingir melhor padrão de qualidade, enseja um ensino pasteurizado, conteudista, antiplural e antidemocrático na medida em que retira a autonomia dos sistemas de ensino, das escolas e dos profissionais da educação. 
Em que medida a definição de uma base nacional comum curricular para o País não estaria incorporada à perspectiva pragmática de um currículo cuja racionalidade explicita ainda uma lógica instrumental e portadora da possibilidade de que se instituam mecanismos de controle sobre as possibilidades formativas de crianças e jovens? A que e a quem serve a ideia de um currículo mínimo nacional? Nesse sentido, as Diretrizes Curriculares Nacionais exaradas pelo Conselho Nacional de Educação, dado seu caráter norteador e menos prescritivo, já não seriam suficientemente definidoras e capazes de respeitar as diferenças regionais, culturais, entre outras?

A proposta de Base Nacional Comum Curricular vai justamente em sentido oposto ao entendimento de que enfrentar as desigualdades passa por respeitar e atentar para a diferença e diversidade de todos os tipos, desde a condição social até as diferenças étnico-raciais, de gênero, sexo etc. A padronização é contrária ao exercício da liberdade e da autonomia, seja das escolas, seja dos educadores, seja dos estudantes em definirem juntos o projeto formativo que alicerça a proposta curricular da escola.

Já no final dos anos 1980 e vigorosamente nos anos 1990, o cenário educacional passa a ter uma novidade que marcará definitivamente as políticas vindouras no País. Trata-se do Sistema de Avaliação da Educação Básica (Saeb). No princípio com avaliações amostrais, o Saeb teve o importante intuito de mapear e nos deixar conhecer aspectos importantes das redes de ensino para a implementação de políticas públicas que visassem à melhoria da educação.

Ao final dos anos 1990 e nos 2000, temos cada vez mais um requinte na configuração e implementação dos testes de larga escala no qual o sistema se baseia. Com o fim da base amostral e a introdução da base censitária, passamos a ter algumas possibilidades que antes não tínhamos: se, por um lado, era possível chegar mais próximo das escolas, por outro, a possibilidade de ranqueamento, de responsabilização de seus profissionais e alunos com os prêmios e castigos, aproximou nossas escolas de uma política mais competitiva, de bônus e de ônus (BALL, 2005; FREITAS, 2012).

Nossas escolas passaram a ser exigidas, pelas políticas implementadas, a trabalhar a partir de uma lógica empresarial, cujo resultado passa a ser o mais importante. Podemos dizer que chegamos à educação do treino e do produto. A avaliação é vista como possibilidade de medição de um conhecimento que, por sua vez, pode ser medido, destituído de qualquer complexidade e subjetividade. Importa um currículo enxuto, um bom treinamento, um professor aplicador de conteúdos e um aluno que responde às avaliações com alternativas, sem desenvolvimento de senso crítico (FERNANDES, 2015, p. 402).

Acrescente-se ainda que a razão de ser da BNCC é a uniformização do ensino num país que se caracteriza por sua diversidade (linguística, cultural, econômica e social). E a uniformização do ensino, ainda que ideologicamente justificada para parecer que vivemos numa sociedade sem desigualdade social e regional, de fato atende a necessidades do projeto neoliberal de educação, que orienta todos os seus horizontes pelas avaliações de larga escala. 
Enfatiza-se que a BNCC pode ser um engessamento, com propostas vinculadas ao mercado, dependendo dos sujeitos e das correlações de força envolvidas no processo.

\section{Lei 13.415/2017 - Reforma do Ensino Médio}

Estabelecida através da Conversão da Medida Provisória nº 746, de 2016, a Lei modificou a LDBEN 9.394/96, que estabelece as diretrizes e bases da educação nacional, para instituir a jornada em tempo integral no ensino médio, dispor sobre a organização dos currículos do ensino médio em áreas do conhecimento, além de outras modificações. Entre as principais mudanças, o projeto estabelece uma carga horária de 800 horas para o ensino fundamental e 1.400 para o ensino médio, distribuídas em 200 dias letivos.

O currículo fica dividido em duas partes: uma parte comum de 1.800 horas a todos/ as estudantes e outra, dividida em cinco itinerários, em que o/a estudante terá que fazer aquilo que escola/sistema ofertar: 1) linguagens e suas tecnologias; 2) matemática e suas tecnologias; 3) ciências da natureza e suas tecnologias; 4) ciências humanas e sociais aplicadas; 5) formação técnica e profissional.

A principal questão a ser destacada neste primeiro momento é a seguinte: ao contrário do que o governo divulga, os itinerários formativos não serão necessariamente escolhidos pelo estudante. Serão contemplados conforme as condições da escola em ofertá-los. A premissa de escolha, especialmente em escolas públicas, portanto, é uma ficção. Diante do déficit histórico e estrutural de recursos humanos nas escolas públicas, não é difícil prever o cenário nessas instituições. Por outro lado, no ensino privado esse quadro poderá configurar-se como novo nicho de mercado e até mesmo como bandeira de marketing, tendo em vista que poderá ofertar maior leque de itinerários.

É possível prever, então, que essa estrutura do ensino médio poderá trazer ainda mais desigualdades, pois os colégios particulares provavelmente manterão todas as disciplinas, o que resultará também no marketing educacional, apresentado pelos autores Marcos Cobra e Ryon Braga. Eles definem o marketing educacional como a utilização de conceitos mercadológicos, via atração de mais alunos para se obter lucros, pois os colégios podem defender que estão lecionando todas as disciplinas.

Por outro lado, o ensino público, já classificado atualmente como "sucateado", fará com que os alunos se dediquem principalmente às áreas de linguagens e matemática, por exemplo. Isso prejudicaria o direito dos estudantes à educação, que prevê o papel da escola como transmissora dos saberes da humanidade. Com a exclusão de conteúdos da grade obrigatória, é claro que os conteúdos não obrigatórios serão trabalhados de maneira displicente, isso se caso forem abordados.

Na escola, mesmo socializadora como todos os processos sociais, deveria preponderar a construção da consciência crítica e autocrítica, dentro da perspectiva da 
formação do sujeito. Educação reclama postura de sujeito. É o cerne da emancipação, que somente medra em sujeitos. Emancipação emerge, quando objetos se apercebem de sua subordinação, e, num processo de conquista, avançam para a condição de sujeitos (DEMO, 2009, p. 100).

As únicas disciplinas obrigatórias nos três anos são Língua Portuguesa e Matemática. É obrigatório ofertar também uma língua estrangeira e, neste caso não há escolha, pois a língua obrigatória é a inglesa, sendo opcional a oferta da língua espanhola. O texto informa que a Base Nacional "incluirá obrigatoriamente estudos e práticas de educação física, arte, sociologia e filosofia". Nota-se que esses campos não são chamados de disciplinas. Na realidade, também não serão obrigatórias, já que poderão ser diluídas em outras disciplinas. O mesmo vale para áreas como geografia, história e química, que ficarão diluídas nos itinerários formativos.

A reforma atinge indiretamente a formação dos novos professores no atendimento a essas demandas. A formação do professor é indispensável porque há saberes e competências que são específicos da docência. Porém, ensinar bem uma matéria não requer apenas saber o conteúdo - é preciso compreender o complexo processo ensino-aprendizagem. Além dos problemas didáticos, não resta dúvida que isso abrirá ainda mais brechas para contratações emergenciais, minando concursos e deslegitimando o sentido dos cursos de licenciatura. Nesse sentido, a Reforma não tem nada de ingênua, servindo como caminho para o estabelecimento da "escola sem partido".

\section{Lei da mordaça: Escola "sem" partido}

O projeto ${ }^{10}$ de Lei 7180/2014 ${ }^{11}$, proposto por Erivelton Santana (Patri-BA), discorre sobre o Escola Sem Partido, que teve votação postergada no mês de julho devido à divergências ${ }^{12}$ entre grupos favoráveis e contrários a ela. O projeto proíbe a abordagem de temáticas de gênero, além de colocar o educando em uma posição de vulnerável ou, a partir de uma leitura mais crítica, como se ele fosse totalmente influenciável pelo educador, o que não se aplica na prática, tendo em vista que o estudante deve ser considerado como sujeito no processo de ensino e aprendizagem. Correm no Congresso Nacional, assembleias legislativas e câmaras de vereadores pelo País um sem número de projetos com o mesmo escopo.

O ministro Luís Roberto Barroso, do Supremo Tribunal Federal (STF), em 2017, decidiu pela inconstitucionalidade da Lei 7.800/2016, do estado de Alagoas, baseada no projeto Escola sem Partido - que se propõe a combater uma suposta "doutrinação ideológica marxista nas escolas". Para o ministro, a norma não tem condições de promover uma educação sem doutrinação. 
O Conselho Nacional de Direitos Humanos, em 23 de agosto de 2017, se manifestou publicamente contra "quaisquer iniciativas, públicas ou particulares, que tenham como objetivo restringir a liberdade de comunicação em ambiente escolar". Em abril do mesmo ano, relatores das Nações Unidas também se posicionaram contra o projeto, classificando-o como "censura".

Com isso, a impressão é que o ensino é uma via de mão única, o que Paulo Freire definiu como educação bancária, na qual o professor apenas "deposita conhecimentos" e os estudantes recebem. Esse modelo está fadado ao fracasso e Paulo Freire considera que “aprender é uma aventura criadora, algo, por isso mesmo, muito mais rico do que meramente repetir a lição dada. Aprender para nós é construir - reconstruir, construir para mudar, o que não se faz sem abertura ao risco e à aventura do espírito" (FREIRE, 1997, p. 77).

A ideia é que os estudantes consigam construir um aprendizado mais crítico e o “diálogo constante com o outro. Que o predispusesse a constantes revisões. À análise crítica, de seus "achados". A uma certa rebeldia. No sentido mais humano da expressão" (FREIRE, 2007, P. 98). Desse modo, o projeto de lei considera a educação bancária como modelo ideal, e não leva em consideração que o estudante é também um agente no meio, e que é ator em sua realidade social.

O projeto estabelecia, ainda, que os educadores deveriam deixar em um cartaz, na sala ou no mural, os conteúdos que seriam ministrados, demonstrando um quê de censura à atividade docente, que também fere a liberdade de cátedra, ou seja, de livre ensino, aprendizagem, pesquisa e divulgação do conhecimento. Além disso fere o artigo 206 da Constituição Federal, que traz:

Art. 206. O ensino será ministrado com base nos seguintes princípios: 7 [...]; II - liberdade de aprender, ensinar, pesquisar e divulgar o pensamento, a arte e o saber; III - pluralismo de ideias e de concepções pedagógicas, e coexistência de instituições públicas e privadas de ensino.

Ao definir conteúdos que não podem ser abordados, o projeto de lei coloca em xeque o modelo de educação livre e se aproxima a um modelo controlado. O projeto da chamada Lei da Mordaça traz na justificativa o seguinte conteúdo:

É fato notório que professores e autores de materiais didáticos vêm se utilizando de suas aulas e de suas obras para tentar obter a adesão dos estudantes à determinadas correntes políticas e ideológicas para fazer com que eles adotem padrões de julgamento e de conduta moral - especialmente moral sexual - incompatíveis com os que lhes são ensinados por seus pais ou responsáveis (BRASIL, PLS 193/2016).

A partir do conteúdo, é possível perceber que há um pré-julgamento da função do professor, que é colocado novamente na posição da educação bancária apresentada por Paulo Freire. Além disso, há um preconceito em relação à figura do educador, apresentado 
como um verdadeiro propagador de ideologias. Os motivos são apresentados sem comprovação científica ou embasamento teórico, o que deixa claro que são apenas "convicções" de que a realidade funciona desta maneira, o que não é percebido no ambiente escolar.

Resumidamente pode-se afirmar que a liberdade de ensinar aparece no texto constitucional como liberdade institucional e como liberdade docente. Em ambos os casos ela é limitada por um conjunto de outros princípios e garantias constitucionais e pela estrutura do sistema educacional brasileiro. Mas em ambos os casos ela é suficiente para garantir o pluralismo de ideias e abordagens pedagógicas e de expressão de pontos de vista acadêmicos, mantendo assim a sua finalidade (RODRIGUES, MARROCO, 2014, p. 6-7).

O projeto "Escola sem Partido", com seus propósitos de eliminação da política como esfera de debate e formação do pensamento livre, tornou-se um instrumento de disputa para respaldar os retrocessos no campo dos Direitos Humanos que se efetivam com o Golpe de 2016. É possível aferir, no entanto, que a escola já tem partido sim: o que objetiva o desmantelamento das políticas públicas, que deseja a formação meramente tecnicista e não preocupada com a formação integral do indivíduo. Essa escola tem o mesmo partido há décadas, e é aquele que não olha pelas camadas mais populares.

\section{Considerações finais}

O setor privado está cada vez mais organizado para dar direção às políticas públicas. No entanto, é possível perceber que o setor privado mercantil, organizado ou não em redes, não é uma abstração. Ele é formado e operado por sujeitos individuais e coletivos em um projeto de classe, sendo parte de uma ofensiva histórica do capital e com especificidades neste período particular do capitalismo.

Enquanto os neoliberais controlam o mercado de trabalho e concebem uma educação mercantilizada, os neoconservadores defendem um currículo oficial centralizado em um conhecimento oficial e no status do professor, que agora é visto como "a" autoridade na sala de aula em termos dos conhecimentos conteudistas. Alinhados à ideia de resgate e reforço da autoridade docente sobre os estudantes, os populistas autoritários, que representam o fundamentalismo cristão, representados na bancada evangélica e com apoio de outros grupos conservadores, defendem ferrenhamente a tradição representada pela família (em oposição ao multiculturalismo, diversidade de expressões familiares e diversidade de gênero) e uma escola autoritária centrada no adulto, ou seja, um espaço educacional não democrático. Para além desses três grupos, o quarto grupo da aliança hegemônica ainda se encontra em processo de crescimento, fortalecimento e reconhecimento na esfera do poder: é o grupo constituído pela nova classe média profissional e administrativa que é bastante influente no estabelecimento da agenda política educativa, 
porque opera dentro da máquina estatal, embora não esteja necessariamente alinhado às concepções dos grupos anteriores.

É necessário conceber a educação e a escola a partir de pressupostos ora em curso no Brasil e que se fundamentam na Constituição Brasileira (BRASIL, 1988) e na LDBEN (BRASIL, 1996), documentos inspirados nos princípios de liberdade, e nos ideais de solidariedade com vistas ao desenvolvimento do estudante e preparo para o exercício da cidadania. Para além desses princípios, a LDBEN fundamenta a educação brasileira nos princípios da

(I) igualdade de condições para o acesso e permanência na escola; (II) liberdade de aprender, ensinar, pesquisar e divulgar a cultura, o pensamento, a arte e o saber; (III) pluralismo de ideias e de concepções pedagógicas; (IV) respeito à liberdade e apreço à tolerância; e (VIII) gestão democrática do ensino público.

Entende-se que a perspectiva salvacionista, de que o privado mercantil deve garantir a qualidade da educação pública, está inserida em uma lógica que naturaliza essa participação, pois parte do pressuposto neoliberal de que não é o capitalismo que está em crise, mas o Estado. A estratégia, para essa concepção, é reformar o Estado ou diminuir sua atuação para superar a crise. O mercado é que deverá superar as falhas do Estado, portanto a lógica do mercado deve prevalecer, inclusive no Estado, para que ele possa ser mais eficiente e produtivo, na perspectiva de quem defende a lógica de mercado.

As disputas por um projeto de construção e consolidação de um sistema nacional de educação público, laico, gratuito democrático e de qualidade não apenas mobilizam múltiplos sentidos para cada um desses termos, mas também e sobretudo produzem fechamentos provisórios e contingenciais com o propósito de universalizar, hegemonizar um sentido particular, atribuído a cada um desses significantes. Ao se posicionar a favor ou contra a implementação de uma base nacional comum curricular e expor argumentos que sustentam posições, as pessoas participam de inúmeras outras disputas em torno da significação (LEITE, 2010) e desses significantes nos múltiplos contextos discursivos nos quais eles são acionados.

É necessário, entre outros pontos, financiamento adequado, condições de trabalho, formação continuada, valorização salarial e profissional dos trabalhadores da educação. Apenas dessa forma as escolas serão capazes de cumprir seu papel social, assegurando inclusão e qualidade do ensino a todos os estudantes.

Sobre a política de avaliação, almejamos outro referencial de avaliação da educação, que seja institucional e que compreenda as ações de gestores, as políticas públicas, as condições de trabalho dos educadores, além da avaliação estudantil.

Seguindo na trajetória de mais investimentos para as escolas públicas, fato é que para se atingir os pressupostos curriculares, outras políticas precisam caminhar pari passu com a base nacional curricular, de forma sistêmica, entre elas, a que garanta o acesso e a 
permanência de todas as crianças e jovens nas escolas, bem como o financiamento necessário para assegurar, em todos os municípios brasileiros, independente da rede de ensino, escolas organizadas, bem equipadas e seguras, com profissionais capacitados, remunerados dignamente e com plenas condições para desenvolver projetos pedagógicos à luz dos princípios da autonomia escolar e da transmissão dos saberes - e sempre conectadas com os anseios sociais de suas comunidades.

Apresentado em: 14/05/2018, reapresentado em: 25/07/2018 e aprovado em: 28/07/2018

\section{Notas}

1 Disponível em: <http://www1.folha.uol.com.br/poder/2013/12/1390207-manifestacoes-nao-foram-pelos-20-centavos.shtml>. Acesso em 07 de abr de 2018.

2 Disponível em: <http://arte.folha.uol.com.br/poder/operacao-lava-jato/\#capitulo1>. Acesso em 07 de abr de 2018.

3 Disponível em: <http://www.mpf.mp.br/para-o-cidadao/caso-lava-jato>. Acesso em 07 de mar de 2018.

4 Disponível em: <http://www.bbc.com/portuguese/brasil-39299007>. Acesso em 07 de mar de 2018.

5 Disponível em: <https://www.eleicoes2014.com.br/candidatos-presidente/>. Acesso em 07 de abr de 2018.

6 Disponível em: <https://www.cartamaior.com.br/?/Editoria/Politica/As-tres-crises-do-governo-Dilma/4/33990>. Acesso em 07 de abr de 2018.

7 Disponível em: <http://www.planalto.gov.br/ccivil_03/constituicao/emendas/emc/emc95.htm>. Acesso em 04 de abr de 2018.

8 Disponível em: <https://oglobo.globo.com/economia/governo-quer-desvincular-gastos-sociais-como-saude-educacao-19372493>. Acesso em 04 de abr de 2018.

9 Disponível em: <http://www.fenafisco.org.br/noticias-fenafisco/item/1197-sistema-tributario-brasileiro-reforca-a-desigualdade-diz-oxfam>. Acesso em 04 de abr de 2018.

10 Disponível em: <http://www.camara.gov.br/proposicoesWeb/prop_emendas?idProposicao=606722\&sub st=1>. Acesso em 24 de jul. de 2018.

11 Projeto ao qual estão apensados também os PLs n. 7.181/2014, 867/2015, 1.859/2015, 5.487/2016, 6.005/2016, 8.933/2017 e 9.957/2018, que versam sobre o mesmo tema. (Nota dos autores).

12 Disponível em: <http://www2.camara.leg.br/camaranoticias/noticias/EDUCACAO-E-CULTURA/560313-DIVERGENCIAS-IMPEDEM-VOTACAO-DO-PARECER-SOBRE-A-\%E2\%80\%9CESCOLA-SEM-PARTIDO\%E2\%80\%9D.html>. Acesso em 24 de jul. de 2018. 


\section{Referências}

APPLE, Michael. Reestruturação educativa e curricular e as agendas neoliberal e neoconservadora: entrevista com Michael Apple. Currículo sem Fronteiras, Rio de Janeiro: Associação Brasileira de Currículo, v. 1, n. 1, p. 5- 33, jan.jun. 2001.

. Ideologia e currículo. 3. ed. Porto Alegre: ArtMed, 2006.

BALL, Stephen. Profissionalismo, gerencialismo e performatividade. Cadernos de Pesquisa, São Paulo: Fundação Carlos Chagas, v. 35, n. 126, p. 539-564, 2005.

. Sociologia das políticas educacionais e pesquisa crítico-social: uma revisão pessoal das políticas educacionais e da pesquisa em política educacional. Currículo sem Fronteiras, Rio de Janeiro, Associação Brasileira de Currículo, v. 6, n. 2, p. 10-32, 2006.

BERSTEIN, Brasil. Classes, códigos e controle. A estruturação do discurso pedagógico. Petrópolis, RJ: Vozes, 1996.

BRASIL. Constituição (1988). Constituição da República Federativa do Brasil. Brasília: 1988. Disponível em: http://www.planalto.gov.br/ccivil_03/constituicao/ConstituicaoCompilado.htm. Acesso em: 23 de mar. 2016.

. Referenciais curriculares nacionais para a educação infantil. Brasília: Ministério da Educação, 1995. Disponível em: http://portal.mec.gov.br/seb/arquivos/pdf/rcnei_vol1.pdf. Acesso em: 23 de mar. 2016.

Lei no 9.394, de 20 de dezembro de 1996. Estabelece as diretrizes e bases da educação nacional. Disponível em: http://www.planalto.gov.br/ccivil_03/leis/L9394.htm. Acesso em: 23 de mar. 2016.

. Lei $\mathbf{n}^{\mathbf{0}}$ 10.639, de 9 de janeiro de 2003. Inclui no currículo oficial da Rede de Ensino a obrigatoriedade da temática "História e Cultura Afro-Brasileira". Disponível em: http://www.planalto. gov.br/ccivil_03/leis/2003/L10.639.htm. Acesso em: 23 de mar. 2016.

. Lei no 11.645 , de 10 de março de 2008. Inclui no currículo oficial da rede de ensino a obrigatoriedade da temática "História e Cultura Afro-Brasileira e Indígena". Disponível em: http:// www.planalto.gov.br/ccivil_03/_ato2007-2010/2008/lei/111645.htm. Acesso em: 23 de mar. 2016.

. Lei n⿳0 13.005, de 25 de junho de 2014. Aprova o Plano Nacional de Educação - PNE e dá outras providências. Disponível em: http://www.planalto.gov.br/ccivil_03/_ato2011-2014/2014/lei/113005.htm. Acesso em: 23 de mar. 2016.

. Ministério da Educação. Base Nacional Comum Curricular - documento preliminar. Brasília: MEC, 2015.

CANDAU, Vera Maria; MOREIRA, Antônio Flávio Barbosa. Indagações sobre currículo: currículo, conhecimento e cultura. In.: BEAUCHAMP, Jeanete; PAGEL, Sandra Denise; NASCIMENTO, Aricélia Ribeiro do. (Orgs). Currículo, conhecimento e Cultura. Brasília: Ministério da Educação/Secretaria de Educação Básica, 2007.

DAGNINO, Evelina; ALVAREZ, S.; DAGNINO, E.; ESCOBAR, A. Cultura e política nos movimentos sociais latino-americanos. Belo Horizonte: UFMG, 2000, pp. 61-102.

FERNANDES, Cláudia de Oliveira. Avaliação, currículo e suas implicações: projetos de sociedade em disputa. Revista Retratos da Escola, Brasília: ESFORCE, v.9, n. 17, p. 397-408, jul./dez, 2015. 
FERNANDES, Domingos. Avaliar para aprender: fundamentos, práticas e políticas. São Paulo: Ed. UNESP, 2009.

FERREIRA, Windyz Brazão. O conceito de diversidade no BNCC - Relações de poder e interesses ocultos. Revista Retratos da Escola, Brasília: ESFORCE, v.9, n. 17, p. 299-319, jul./dez, 2015.

FREIRE, Paulo. Educação como prática de liberdade. Rio de Janeiro, Paz e Terra, 2007.

1997.

Pedagogia da Autonomia: Saberes necessários à prática educativa. Rio de Janeiro: Paz e Terra,

FUNDAÇÃO LEMANN. Relatório Anual 2014. Disponível em: http://www.fundacaolemann.org.br/ wp-content/uploads/2014/10/RA_2014_final-embaixa.pdf. Acesso em: 23 de mar. 2016.

FREITAS, Luiz Carlos. Qualidade negociada: avaliação e contra regulação da escola pública. Educação e Sociedade, Campinas: Unicamp, v. 26, n. 92, p. 911-933, 2005.

. Os reformadores empresariais da educação: da desmoralização do magistério à destruição do sistema público de educação. Educação e Sociedade, Campinas: Unicamp, v. 33, n. 119, p. 379-404, 2012.

HABERMAS, Jürgen. Direito e democracia. V.II. Rio de Janeiro: Tempo Brasileiro, 1997, pp. 57-121.

LEITE Miriam Soares. Adolescência e juventude no ensino fundamental: significações no contexto da prática curricular. Revista Teias, Rio de Janeiro: UERJ, v.11, n. 22, p. 55-74, maio/agosto, 2010.

LIMA, Elvira Souza. Neurociência e Currículo. São Paulo: Editora Interalia, 2015.

Neurociência e Aprendizagem. São Paulo: Editora Interalia, 2010.

LOPES, Alice. Por um currículo sem fundamentos. Linhas Criticas, Brasília: DE, v.21, n.45, p.445-466, mai./ago. 2015.

MARIANO, Cynara Monteiro. Emenda constitucional 95/2016 e o teto dos gastos públicos: Brasil de volta ao estado de exceção econômico e ao capitalismo do desastre. Revista de Investigações Constitucionais, Curitiba: UFPR, v. 4, n. 1, p. 259-281, jan./abr. 2017.

SILVA, João Paulo de Souza ; MEI, Danielle Scheffelmeier. Para nunca esquecer: os "massacres" de 30 de agosto e de 29 de abril. In: SANTOS, Joana Ribeiro dos; ROSA, Rebeca Silva Brandão. (Orgs.). Ativismo, movimentos sociais e educação. Rio de Janeiro: Dictio Brasil, 2017, v. 1, p. 197-219.

NOBRE, Marcos. Choque de democracia: razões da revolta. São Paulo: Companhia das Letras, 2013.

NÓVOA, Antônio. Modelos de análise em educação comparada: o campo e a carta. In: SOUZA,

Donaldo Bello de; MARTINEZ, Silvia Alícia. (Orgs). Educação Comparada: rotas de além mar. São Paulo: Xamã, 2009.

OLIVEIRA, Antônio Angirlucio. Implicações para as práticas docentes da política da SME do Rio de Janeiro concretizada nas avaliações externas. 2015. Dissertação (Mestrado). Programa de PósGraduação em Educação, Unirio, Rio de Janeiro, 2015.

SACRISTAN, J. Gimeno. Poderes instáveis em educação. Porto Alegre: Artmed, 1999.

Reformas educativas y reformas delcurriculo. In: WARDE, Mirian Jorge (Org.). Novas políticas educacionais: críticas e perspectivas. São Paulo: PUC/SP, 1998.

SILVA, Tomaz Tadeu da. Documentos de identidade: uma introdução às teorias do currículo. Belo Horizonte: Autêntica, 1999. 
VEIGA, João Marcos. Base Nacional Comum: currículo para a educação básica em disputa. Anped, 2015. Disponível em: http://anped.org.br/news/base-nacional-comum-curriculo-para-educacao-basicaem-disputa. Acesso em 23 de mar. 2016.

LUDKE, Menga. O professor, seu saber e sua pesquisa. Educação \& Sociedade, Campinas: Unicamp, v. 22, n. 74, p. 77-96, 2001. Disponível em: <http://www.scielo.br/scielo.php?script=sci_ arttext\&pid=S010173302001000100006\&lng=pt\&nrm=iso $>$. Acesso em: 08 jul. 2008.

PASINATO, Nara Maria Bernardes. Proposta de indicadores para avaliação dos estágios de integração das TIC na prática pedagógica do professor. 2011. 138 f. Dissertação (Mestrado) - Pontifícia Universidade Católica do Paraná, Curitiba, 2011.

VOSGERAU, Dilmeire Sant 'Anna Ramos. A tecnologia nas escolas: o papel do gestor neste processo. In: BARBOSA, Alexandre (Coord.). Pesquisa sobre o uso das tecnologias de informação e comunicação no Brasil: TIC Educação 2011. São Paulo: Comitê Gestor da Internet no Brasil, 2012. p.35-45. 